\title{
Partial monosomy 8p and trisomy 16q in two children with developmental delay detected by array comparative genomic hybridization
}

\author{
ZOE PAPADOPOULOU ${ }^{1}$, IOANNIS PAPOULIDIS ${ }^{2}$, STAVROS SIFAKIS ${ }^{3}$, GEORGIOS MARKOPOULOS ${ }^{1,4}$, \\ ANNALISA VETRO $^{5}$, ANGELIKI-MARIA VLAIKOU ${ }^{1}$, MONICA ZIEGLER $^{6}$, THOMAS LIEHR ${ }^{6}$, \\ LORETTA THOMAIDIS $^{7}$, ORSETTA ZUFFARDI ${ }^{5}$, MARIA SYRROU ${ }^{1}$, \\ KITSOS GEORGE $^{8}$ and EMMANOUIL MANOLAKOS ${ }^{2,9}$
}

\begin{abstract}
${ }^{1}$ Laboratory of Biology, Faculty of Medicine, School of Health Sciences, University of Ioannina, Ioannina 45110;
${ }^{2}$ Access To Genome, Laboratory of Genetics, Athens 11528-Thessaloniki 55134; ${ }^{3}$ Department of Obstetrics and Gynecology, University Hospital of Heraklion, Heraklion 71201; ${ }^{4}$ Biomedical Research Division, Institute

of Molecular Biology and Biotechnology, Foundation of Research and Technology, University Campus,

Ioannina 45110, Greece; ${ }^{5}$ Department of Molecular Medicine, University of Pavia, I-27100 Pavia, Italy; ${ }^{6}$ Jena

University Hospital, Friedrich Schiller University, Institute of Human Genetics, D-07743 Jena, Germany;

${ }^{7}$ Developmental Assessment Unit, 2nd Department of Pediatrics, P. \& A. Kyriakou Children's Hospital, National and Kapodistrian University of Athens School of Medicine, Athens 11527; ${ }^{8}$ Department of Ophthalmology, University of Ioannina, Ioannina 45110, Greece; ${ }^{9}$ Department of Medical Genetics, University of Cagliari, I-09124 Cagliari, Italy
\end{abstract}

Received January 28, 2016; Accepted February 7, 2017

DOI: $10.3892 / \mathrm{mmr} .2017 .7760$

\begin{abstract}
Two cases of liveborn unrelated children with developmental delay and overlapping unbalanced translocations $\operatorname{der}(8) \mathrm{t}(8 ; 16)(\mathrm{p} 23.2 ; \mathrm{q} 23.3)$ and $\operatorname{der}(8) \mathrm{t}(8 ; 16)(\mathrm{p} 23.1 ; \mathrm{q} 23.1)$, leading to partial monosomy $8 \mathrm{p}$ and partial trisomy $16 \mathrm{q}$, are reported in the present study. The first patient was a 10 -year-old boy with mild developmental delay and minor congenital anomalies (borderline microcephaly, clinodactyly, hypertelorism, epicanthus, mild systolic murmur and kidney reflux). The second patient was a 3 year-old girl with developmental delay, gross motor milestone delay and dysmorphic features. Array-comparative genomic hybridization analysis revealed that partial chromosome 8p monosomy extended from 8p23.2 to 8 pter $(4.8 \mathrm{Mb})$ in Patient 1 and from 8 p23.1 to 8 pter $(9.5 \mathrm{Mb})$ in Patient 2, and partial chromosome 16 trisomy extended from 16q23.3 to 16qter (5.6 Mb) in Patient 1 and from 16q23.1 to 16 qter $(11.7 \mathrm{Mb})$ in Patient 2 . The mechanism of appearance of the rearrangement in association with the genes involved and the architecture of the region is discussed.
\end{abstract}

Correspondence to: Dr Stavros Sifakis, Department of Obstetrics and Gynecology, University Hospital of Heraklion, 228 Oulof Palme Street, Heraklion 71201, Greece

E-mail: stavros.sifakis@yahoo.com

Key words: translocation, monosomy 8p, trisomy 16q, array comparative genomic hybridization, developmental delay, congenital abnormalities

\section{Introduction}

Monosomy $8 \mathrm{p}$ is a rare chromosomal disorder characterized by deletion of a part of the eighth chromosome. The incidence of the 8p23.1 deletion was estimated at 1:18,542 in amniotic fluid samples and 1:5,072 in postnatal samples (1). Since the first report of an 8p23.1 deletion by Fagan and Morris (2), $>50$ cases have been reported (3). The majority of the cases are not studied with high resolution molecular techniques or characterized at the molecular level (4). Interstitial deletions of the sub-band 8p23.1 have primarily been associated with facial and other phenotypic abnormalities, whereas terminal deletions are associated with heart defects $(3,5)$. Notably, distal deletion of 8p23.2-pter has additionally been observed in apparently healthy individuals (1).

In the majority of cases, monosomy $8 \mathrm{p}$ appears to result from de novo errors in early embryonic development that occur for unknown reasons. Associated symptoms and findings differ between cases (6). However, in most cases clinical manifestations including growth deficiency, mental retardation, post-natal growth retardation, developmental delay and speech problems are observed. Furthermore, patients present with common signs of body and craniofacial dysmophisms, in addition to behavioral difficulties $(1,3,5,6)$. Facial dysmorphisms, which are more remarkable in early years, include microcephaly, malformed or low set ears, arched eyebrows, depressed nasal bridge, epicanthus, strabismus, hypermetropia and/or myopia, serrated teeth, short neck and retrognathia. In addition, vertebral abnormalities are frequently observed (7-11).

It has additionally been reported that children with this chromosomal disorder present with behavioral difficulties, including 
aggressiveness and attention deficit disorder, and problems associated with cardiovascular and central nervous system $(5,9,12)$. Furthermore, genito-urinary anomalies, in particular cryptorcidism and hypospadias, are observed in boys (6).

In contrast to $8 \mathrm{p}$ deletion syndrome, partial trisomies of the terminal 16qter are rare (1). A total of nine cases of partial distal chromosome 16 trisomy have been reported but only a few were studied with high resolution molecular techniques. Only one patient presented a pure partial trisomy 16q24.1q24.3, whereas all the others corresponded to unbalanced translocations where 16q24 was rearranged with other chromosome regions $(7,8,10,11,13-15)$. For two of the patients, there was no detailed phenotypic information $(10,15)$. A number of clinical characteristic features were common in all patients (low birth weight, growth retardation, intellectual disability, muscular hypotonia, small palpebral fissures, long philtrum, low set/dysplastic ears and osteochondroma), so it is difficult to characterize with precision the $16 \mathrm{q} 24$ trisomy phenotype or to establish a genotype-phenotype correlation (11) (Table I).

In the present study, two cases of liveborn unrelated children with an unbalanced 8;16 translocation resulting in partial monosomy of chromosome 8 and partial trisomy of chromosome 16 were reported. The effect on the phenotype of monosomy 8 seems to be more prominent than that of trisomy 16 . However, this phenotype may result from the rearranged architecture of the region, the structure and function of the genes and regions involved, and their interactions.

\section{Patients and methods}

Ethical approval. The present study was approved by the Ethics Committee of the P. \& A. Kyriakou Children's Hospital (Athens, Greece) and was performed with respect to the ethical standards of the Declaration of Helsinki, as revised in 2008. Written, informed consent was obtained from the patient's families.

Patient 1. Patient 1 was a 10- and a half-year-old boy, and the second child of healthy, unrelated parents. The first child of the family is a 16-year-old healthy boy. Patient 1 was referred for developmental assessment for speech and language delay. The patient was born following an uncomplicated full term pregnancy with birth weight $3.350 \mathrm{~kg}$, height $51 \mathrm{~cm}$ and head circumference (HC) $35 \mathrm{~cm}$. The perinatal history was non-significant. At the age of 8 months the patient was diagnosed with a urinary tract infection and an X-ray investigation revealed urinary reflux (V degree), and a kidney dimercaptosuccinic acid scan revealed $20 \%$ decreased left kidney function. The developmental milestones of the patient were slightly delayed as he sat independently at the age of 9 months and walked unaided at the age of 18 months.

On developmental examination at 3 years old the patient was a sociable child, with mild dysmorphic facial and body features including microcephaly, hypertelorism, epicanthus, and clinodactyly. The patient demonstrated good ability for symbolic play and his comprehension ability was limited to one concept per sentence. His speech was limited to 3-4 simple words. His overall developmental level was equivalent to 18 months. According to the Bailey's Scales of Infant Development 2nd edition (16), his mental score was 51 and motor score was 95 . Heart auscultation revealed a mild systolic murmur. On neurological examination, the patient was revealed to be slightly hypertonic with borderline microcephaly $(\mathrm{HC}=48 \mathrm{~cm} ; 3 \%)$.

Echocardiography revealed a small ventricular septal defect without hemodynamic alterations. Metabolic screening revealed a mild elevation of glutamate in blood amino acids and small proteinuria involving lysine, arginin and cystin. His bone age was increased (equivalent to 6-year-old boy). Thyroid function, brain magnetic resonance imaging scans, visual and audiological examinations, urine amino acids and blood lactic acid levels were healthy.

The patient attended mainstream kindergarten and received early intervention services twice a week based on a Portage Scheme. His development was followed up at regular intervals in the Developmental Unit and was monitored according to his needs.

At the age of 3 years and 9 months, his cognitive and language skills were equivalent to the level of a 20-month-old, with severe behavioral difficulties characterized by frequent temper tantrums. At the age of 4 years, 3 months, the cognitive abilities of the patient increased to the level of a 30-month-old while his language skills remained at a 26-month level. His behavior had improved but he remained a difficult child, presenting with hyperactivity, aggressiveness and impulsiveness.

He was additionally observed at the age of 5 years and 2 months. He had made significant developmental progress and his cognitive skills were equivalent to a 4 year and 6 month level, with language skills equivalent to a 2 year and 9 month level. According to Griffiths Scales (17), his performance developmental subquotient (DQ) was 87 and his language DQ was 51 . His weight was $19 \mathrm{~kg}$ (50th centile), his height was $107 \mathrm{~cm}$ (20th centile) and his HC was $49.5 \mathrm{~cm}$ (3rd centile). The dysmorphia of his facial features remained mild and passed unnoticed. He was well integrated in mainstream kindergarten and his parents were planning to place him in a mainstream school with extra educational help.

The patient was re-evaluated at the age of 7 years. He was well integrated into the 1st grade of mainstream primary school with special educational provision. His behavior had significantly improved and he was sociable and co-operative. His cognitive abilities were increased, with a developmental level of 5 years and 8 months with a general DQ of 86 . His weight was $24 \mathrm{~kg}$ (25th centile), his height was $119 \mathrm{~cm}$ (25th centile) and his HC was $49.5 \mathrm{~cm}$ (below 3rd centile). Dysmorphia of his body and facial features remained mild. On neurological examination, he was revealed to be slightly hypertonic. His thyroid functions and detailed endocrinological examination (GH, IGF1, prolactin, LH, FSH, 17-OH prog., cortisol, insulin) proved normal. Previous echo-triplex results additionally proved normal.

The patient was last observed at the age of 10 years and 6 months. He was attending the 3rd grade of the same mainstream primary school with special educational support. He remained sociable with severe attention deficit disorder, impulsivity and lack of self-confidence. His cognitive deficits were more evident in reading and mathematics. His developmental level was equivalent to that of a healthy 6-year-old, with mild phonological and morphological language problems. His general DQ was 78. The dysmorphia of his body and 
Table I. Clinical characteristics associated with 8p23 and 16q24 regions in the literature.

\begin{tabular}{|c|c|c|c|c|c|c|c|c|}
\hline Clinical characteristics & $\begin{array}{l}8 \mathrm{p} 23.1 \\
\rightarrow \text { pter }\end{array}$ & $\begin{array}{l}8 \mathrm{p} 23.2 \\
\rightarrow \text { pter }\end{array}$ & $\underset{\rightarrow \mathrm{qter}}{16 \mathrm{q} 24.1}$ & $\underset{\rightarrow \text { qter }}{16 \mathrm{q} 24.1}$ & Patient 1 & Patient 2 & $\begin{array}{l}\text { Other } \\
\text { studies }\end{array}$ & Total \\
\hline Prematurity & & & & & - & + & & \\
\hline Post-natal growth retardation & + & - & - & + & - & - & $7-12$ & $7 / 15$ \\
\hline Low birth weight & - & - & - & + & - & - & $7,8,11$ & $3 / 3$ \\
\hline Developmental delay & + & - & - & - & + & + & $5,9,12$ & $15 / 20$ \\
\hline Mental retardation & + & + & - & + & - & - & $5,6,9,10$ & $14 / 20$ \\
\hline \multicolumn{9}{|l|}{$\begin{array}{l}\text { Behavioral/ } \\
\text { neurodevelopmental }\end{array}$} \\
\hline $\begin{array}{l}\text { (hyperactivity, aggressiveness, no self- } \\
\text { confidence, attention deficit disorder, anxious) }\end{array}$ & + & - & - & - & + & + & $5,9,12$ & $25 / 58$ \\
\hline \multicolumn{9}{|l|}{ Dysmorphic craniofacial features } \\
\hline Microcephaly & + & + & - & - & + & - & $5,6,9,12$ & $13 / 21$ \\
\hline Hypertelorism & & & & & + & + & & \\
\hline Epicanthus & - & - & - & + & + & + & $7,12,14$ & $4 / 5$ \\
\hline Broad forehead & & & & & - & + & & \\
\hline Arched eyebrows & + & + & - & - & - & + & 6 & $1 / 1$ \\
\hline Diffuse depigmentation of retina & & & & & - & + & & \\
\hline Alternating esotropia & & & & & - & + & & \\
\hline Long philtrum & - & - & - & + & - & + & $10,11,14$ & $3 / 5$ \\
\hline Thin face & & & & & - & + & & \\
\hline Thin lips & + & - & - & + & - & + & 9,14 & $5 / 9$ \\
\hline Small mouth & & & & & - & + & & \\
\hline Retrognathia & + & - & - & - & - & + & 9 & $8 / 8$ \\
\hline Depressed nasal bridge & + & + & - & - & - & + & 6,9 & $2 / 9$ \\
\hline Dysplastics/low set ears & + & - & - & + & - & + & $5,7,8,9,11,12$ & $12 / 23$ \\
\hline \multicolumn{9}{|l|}{ Major malformations } \\
\hline Clinodactyly & & & & & + & - & & \\
\hline Laryngeal stridor/laryngomalacia & + & + & - & - & - & + & 6 & $1 / 1$ \\
\hline Cardiovascular system problems & + & + & - & - & + & - & $6 ; 16$ & $3 / 3$ \\
\hline Abdominal distension & & & & & - & + & & \\
\hline Necrotizing enterocolitis & & & & & - & + & & \\
\hline Genito-urinary anomalies & + & + & - & - & + & - & $5,6,9$ & $9 / 28$ \\
\hline \multicolumn{9}{|l|}{ Central nervous system } \\
\hline Speech problems & + & - & - & - & + & - & $5,9,12$ & $5 / 20$ \\
\hline Dystonic posturing & & & & & - & + & & \\
\hline Myelination delay & & & & & - & + & & \\
\hline
\end{tabular}

facial features (microcephaly, hypertelorism, epicanthus and clinodactyly) was more evident. On neurological examination, he remained slightly hypertonic with brisk reflexes but without focal neurological signs. His weight was $34 \mathrm{~kg}$ (25th centile), his height was $140 \mathrm{~cm}$ (25th centile) and his $\mathrm{HC}$ was $49.5 \mathrm{~cm}$ $(<3$ rd centile).

Patient 2. Patient 2 was a girl was born to non-consanguineous healthy parents at 36 weeks of gestational age, following a normal pregnancy and an uncomplicated delivery. Prenatal karyotype was performed due to advanced maternal age, and it was normal. The family history was unremarkable and there was no previous history of infertility or spontaneous abortion prior to this pregnancy. The birth weight was
2,400 g (25th centile), height $48 \mathrm{~cm}$ (75th-90th centile), and HC $30.5 \mathrm{~cm}$ (2nd-10th centile). Apgar scores were 9 and 10 at 1 and $5 \mathrm{~min}$, respectively.

Two days following birth, the patient presented with abdominal distension and bloody stools. An X-ray revealed the presence of air outside the intestines in the abdominal cavity. Necrotizing enterocolitis with perforation was diagnosed and surgical removal of the caecum was performed, and the ileocecal valve was perforated. However, three months following surgery, she presented with intestinal obstruction caused by narrowing of the previously diseased bowel, requiring further surgical intervention. In addition, the neonatal period was complicated by laryngeal stridor due to laryngomalacia. Some dysmorphic features and dystonic posturing were noticed in 
Table II. Genotypic information of Patient 1 at the chromosome 8 STS markers obtained by quantitative polymerase chain reaction and gene dosage assay.

\begin{tabular}{|c|c|c|c|c|c|c|}
\hline STS name & Gene & Position (bp) & Deletion & Primer & Sequence ('5-3’) & size \\
\hline STS-N21307 & LOC286161 & $427685-427914$ & Yes & $\begin{array}{l}\mathrm{F} \\
\mathrm{R}\end{array}$ & $\begin{array}{l}\text { CAGGTTGGCAAGTGAAATAC } \\
\text { GCAGTAGTGGCATGAAGC }\end{array}$ & 230 \\
\hline SHGC-149177 & DLGAP2 & $952948-953243$ & Yes & $\begin{array}{l}\mathrm{F} \\
\mathrm{R}\end{array}$ & $\begin{array}{l}\text { GCCTCCTGGGATAAAAATCCTTT } \\
\text { GGTTTGCTCTCCTGATTTAGGGT }\end{array}$ & 296 \\
\hline SHGC-149177 & CLN8 & $1728163-1728478$ & Yes & $\begin{array}{l}\mathrm{F} \\
\mathrm{R}\end{array}$ & $\begin{array}{l}\text { AAGAGCAAGAGGAGCAGGAAAAC } \\
\text { GTGAAACATGTGAATCATCAGCC }\end{array}$ & 316 \\
\hline SHGC-105022 & CSMD1 & $4126904-4127196$ & Yes $^{\mathrm{a}}$ & $\begin{array}{l}\mathrm{F} \\
\mathrm{R}\end{array}$ & $\begin{array}{l}\text { TTTTATTTTGGATCAGGCAACCT } \\
\text { TGTGCTTTGAACCACACTCCTAA }\end{array}$ & 293 \\
\hline RH119760 & CSMD1 & $4950952-4951296$ & Yes & $\begin{array}{l}\mathrm{F} \\
\mathrm{R}\end{array}$ & $\begin{array}{l}\text { TATCCAGTCTCTGCATTTGATGG } \\
\text { AGAATCCCAAAGGAGTTACCGAA }\end{array}$ & 345 \\
\hline A004X20 & MCPH1 & $6302850-6303049$ & Yes & $\begin{array}{l}\mathrm{F} \\
\mathrm{R}\end{array}$ & $\begin{array}{l}\text { TAAGTTTTCCTTCTCTTCTGTAG } \\
\text { AAGGACATGATGATGATT }\end{array}$ & 216 \\
\hline SHGC-77726 & MCPH1 & 6478893-6479173 & Yes $^{\mathrm{a}}$ & $\begin{array}{l}\mathrm{F} \\
\mathrm{R}\end{array}$ & $\begin{array}{l}\text { GAAGTAAACTGCAACAGTTCGCC } \\
\text { TCTTCTTTCCGCTGTAGGGC }\end{array}$ & 281 \\
\hline RH120376 & TDH & $11224233-11224519$ & No & $\begin{array}{l}\mathrm{F} \\
\mathrm{R}\end{array}$ & $\begin{array}{l}\text { AAAATCCACGCTTTGACCTAACA } \\
\text { TGGTAAGGGAATGAGTGTGTTCA }\end{array}$ & 287 \\
\hline RH11694 & GATA4 & $11617203-11617417$ & No & $\begin{array}{l}\mathrm{F} \\
\mathrm{R}\end{array}$ & $\begin{array}{l}\text { TGCACATTGCTGTTTCTGCC } \\
\text { GTTTGTGGGTTAGGGAGGGT }\end{array}$ & 234 \\
\hline
\end{tabular}

${ }^{\mathrm{a}}$ One in three replications provided conflicting results. STS, sequence tagged site.

early infancy. The patient acquired head control at the age of 6 months, trunk control at the age of 9 months, and autonomous deambulation at the age of 12 months. The patient started to speak at two years of age, but then stopped any further development of verbal language and developed a preference for gestural communication. Verbal comprehension was good.

Extensive studies for metabolic diseases (including blood and urine amino acids, urine organic acids, blood lactate, pyruvate and ammonia) gave normal results. Electroencephalogram, audiometric examination, cardiological evaluation including echocardiogram, X-rays of the thorax and renal ultrasound returned normal results. Ophthalmologic assessment (at 3 months of age) revealed diffuse depigmentation of the retina. Brain magnetic resonance (at 6 months of age) revealed myelination delay. At 7 months of age, the patient's height was $62 \mathrm{~cm}$ (10th centile), weight was $5.035 \mathrm{~g}(<3 \mathrm{rd}$ centile) and HC was $39.5 \mathrm{~cm}$ (<2nd centile). Morphological evaluation evidenced a thin face, broad forehead, low-set and posteriorly rotated ears, bilateral pits above the tragus, arched eyebrows, hypertelorism, epicanthus inversus, depressed nasal bridge, long philtrum, thin lips, small mouth with down-turned corners, and retrognathia. Neurological examination revealed developmental delay, with gross motor milestones limited to uncompleted head control. Dystonic axial posturing and fluctuating muscular tone of the four limbs was present. Alternating esotropia was additionally observed.

Cytogenetic and fluorescence in situ hybridization (FISH) analyses. Chromosome analysis was performed from 2-2.5 ml cultured blood lymphocytes using Giemsa banding and high resolution banding techniques obtained following cell culture synchronization and thymidine incorporation. FISH studies were performed using a set of probes specific for $8 \mathrm{p}$ (TelVysion 8p SpectrumGreen D8S504) and 16q (TelVysion 16q SpectrumOrange 16qTEL013) subtelomeres according to the manufacturer's protocol (Vysis; Abbott Molecular, Des Plaines, Illinois, USA) (18). The slides were washed and counterstained with 4',6-diamidino-2-phenylindole, and cells were examined under a Zeiss Axioplan II, Imager.M1/Imager.Z1 fluorescence microscope equipped with a triple-bandpass filter (Zeiss GmbH, Jena, Germany). Digital images were captured and stored with Isis software version 3.4.0 (MetaSystems, Altlussheim, Germany).

Array comparative genomic hybridization (aCGH), polymerase chain reaction $(P C R)$ and microsatellite analysis. High molecular weight genomic DNA was extracted from the patient's blood lymphocytes using aQiamp DNA Blood Midi kit (Qiagen, Inc., Valencia, CA, USA). aCGH analysis was performed with DNA from cultured amniocytes in order to characterize the extent of the deletion in Patient 1 and to justify the clinical findings in Patient 2. Molecular karyotyping was performed via oligonucleotide aCGH platforms using an $100 \mathrm{~kb}$ resolution array kit 44K (Agilent Technologies, Inc., Santa Clara, CA, USA). Gene dosage for 9 sequence tagged sites (STSs) from chromosome 8 was performed by PCR using the LightCycler FastStart DNA Master SYBR Green 1 Kit (Roche Diagnostics, Monza Italy), according to the manufacturer's instructions, on a Roche LightCycler 1.5 instrument (Roche Diagnostics). Primer sequences for the telomeric STSs amplified, including the genesceroid-lipofuscinosis, neuronal 8 (CLN8), CUB and Sushi multiple domains 1 (CSMD1), microcephalin 1 primary autosomal recessive $1(M C P H 1)$ and GATA binding protein 4 (GATA4), are listed in Table II. Altogether, 

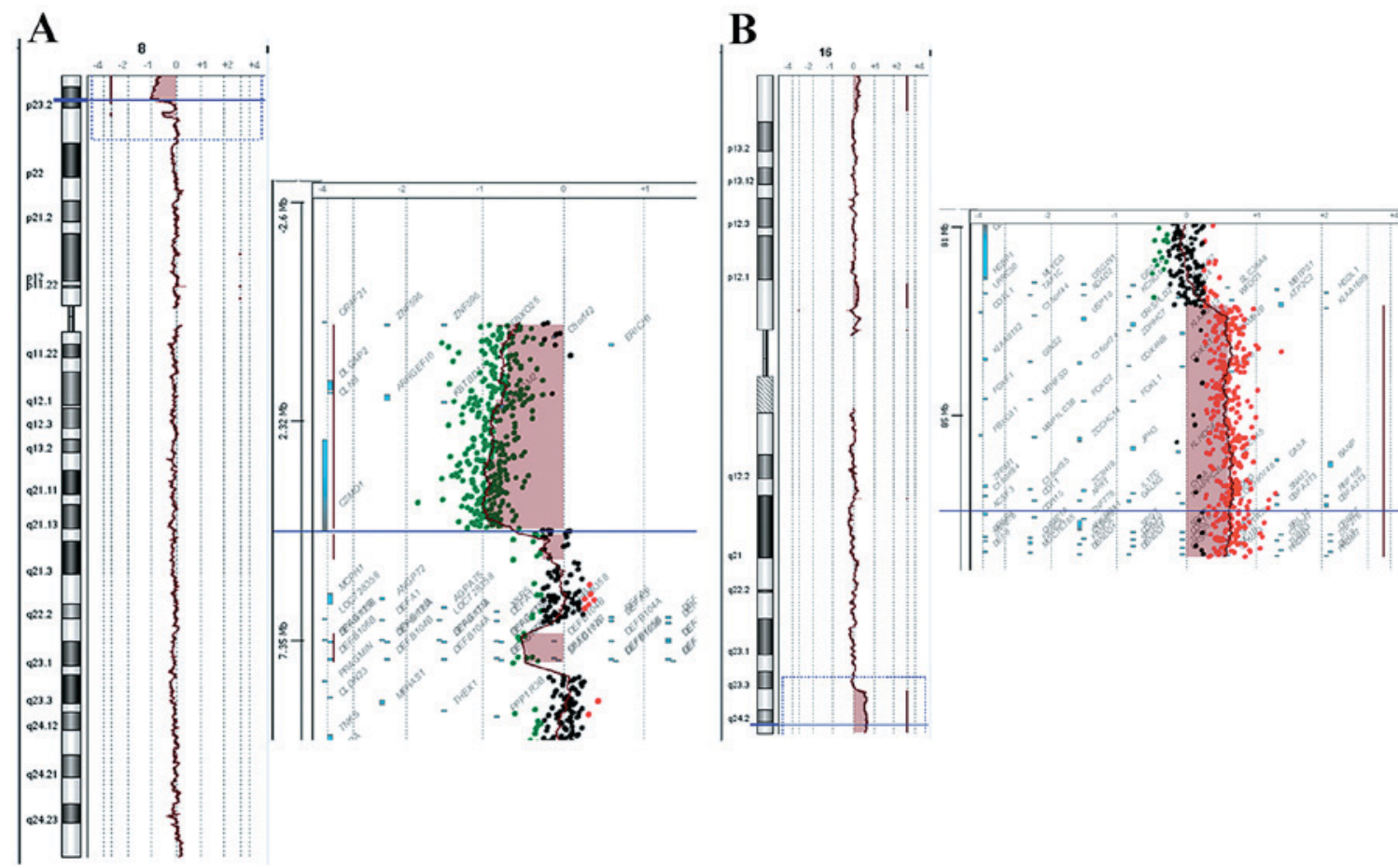

Figure 1. Array comparative genomic hybridization results for Patient 1. (A) De novo 4,8 Mb deletion in the short arm of chromosome 8 located at the 8p23.1 to 8 pter. (B) De novo $5,6 \mathrm{Mb}$ duplication in the long arm of chromosome 16 located at the $16 \mathrm{q} 24.1$ to $16 \mathrm{qter}$.

the analyzed region covered $\sim 11 \mathrm{Mb}$ of DNA of the telomeric $8 \mathrm{p}$ region. PCR was performed using the following program: $95^{\circ} \mathrm{C}$ for $10 \mathrm{~min}$, followed by 40 cycles of $95^{\circ} \mathrm{C}$ for $10 \mathrm{sec}$, $55^{\circ} \mathrm{C}$ for $10 \mathrm{sec}$, and $72^{\circ} \mathrm{C}$ for $25 \mathrm{sec}$. Copy-number/genome of each STS was evaluated by a relative quantification method using the software RelQuant (Roche Diagnostics). A 156 bp fragment of the human beta-globin gene (HBB) was used as reference DNA for normalization and amplified in separate capillaries simultaneously to the STS targets. Primer sequences for HBB were as follows: forward 5'-CAGCTCACTCAGTGT GGCAAAG-3' and reverse 5'-AGGTTCTTTGAGTCCTT TGGGG-3'. Relative standard curves were produced using 5 control DNA samples to correct for differences in efficiency of amplification between STS target and reference DNA. For each locus the test was replicated three times.

Bioinformatic analyses. Sequence features of $8 p$ and $16 q$ regions were analysed in the University of California Santa Cruz (UCSC) Genome Browser (19) using data from the International Standards for Cytogenomic Arrays Consortium (ISCA; www.iscaconsortium.org/) database $(20,21)$ and the corresponding data track for UCSC genes. The Basic Local Alignment Search Tool (BLAST) algorithm (http://blast.ncbi. nlm.nih.gov/Blast.cgi) was used for analysis (22). The results were used to study the nucleotide sequence similarity between the breakpoint regions.

\section{Results}

Patient 1. The conventional karyotype of Patient 1 revealed 'additional' material in the short arm of chromosome 8 (46, $\mathrm{XY}, 8 \mathrm{p}+$ ). aCGH analysis revealed the chromosomal origin of the additional material and the exact position of the breakpoints, namely a deletion of $8 p$ and a duplication of $16 q$. The $8 \mathrm{p}$ deletion was a $4,8 \mathrm{Mb}$ deletion of the distal short arm of chromosome 8 with the proximal breakpoints between 4,814,649 bp (last deleted oligo) and 4,833,351 bp (first normal oligo), with the last oligonucleotide present in the array at 8 p position $161,472 \mathrm{~kb}$ being deleted (Fig. 1A). The deleted region of the CSMD1 gene began at the first intron. The $16 \mathrm{q}$ duplication was a $5.6 \mathrm{Mb}$ duplication of the long arm of chromosome 16 with the proximal breakpoint between $84,468,454$ bp (normal) and 84,511,640 bp (duplicated), and the last oligonucleotide present in the array at $16 \mathrm{q}$ position $88,690,571$ bp being duplicated (Fig. 1B). The size of the breakpoint intervals were 18,702 bp for $8 p$ and 43,186 bp for 16q. The analysis revealed an unbalanced translocation, and the aCGH karyotype was 46,XY,der(8)t $(8 ; 16)(\mathrm{p} 23.2 ; \mathrm{q} 23.3)$ dn.arr[hg18]8p23.3p23.2(151,472-4814649)x 1,16q23.3q24.3 $(84,511,640-88,690,571) \times 3$.

A list of Online Mendelian Inheritance in Man (OMIM; https://www.omim.org/) genes deleted and duplicated is presented in Table III. FISH analysis was performed to confirm the aCGH data. Three signals were detected; one on chromosome 8 and two on chromosome 16 of the 16q subtelomeric probe. FISH analysis performed in the parents revealed a normal result, indicating a de novo rearrangement.

Patient 2. Prenatal diagnosis due to elevated maternal age revealed a normal karyotype of $46, \mathrm{XX}$. During the neonatal period and due to dysmorphic features, hypotonia and clinical complications, aCGH analysis was performed. The analysis revealed a deletion of $9.5 \mathrm{Mb}$ of the distal short arm of chromosome 8 with the proximal breakpoints between 95,48,146 bp (last deleted oligo) and 95,62,020 bp (first normal oligo), with the last oligonucleotide present in the array at $8 \mathrm{p}$ position 
Table III. List of OMIM genes deleted and duplicated in both patients.

Deletion

\begin{tabular}{|c|c|c|c|}
\hline \multicolumn{2}{|c|}{ Patient 1} & \multicolumn{2}{|c|}{ Patient 2} \\
\hline Gene & OMIM & Gene & OMIM \\
\hline$F B X 025$ & 609098 & $F B X 025$ & 609098 \\
\hline$D L G A P 2$ & 605438 & $D L G A P 2$ & 605438 \\
\hline CLN8 & 607837 & CLN8 & 607837 \\
\hline ARHGEF 10 & 608136 & ARHGEF 10 & 608136 \\
\hline MYOM2 & 603509 & MYOM2 & 603509 \\
\hline \multirow[t]{20}{*}{ CSMD1 } & 608397 & CSMD1 & 608397 \\
\hline & & МСРH1 & 607117 \\
\hline & & $A N G P T 2$ & 601922 \\
\hline & & AGPAT5 & 614796 \\
\hline & & $D E F B 1$ & 602056 \\
\hline & & DEFA6 & 600471 \\
\hline & & DEFA4 & 601157 \\
\hline & & DEFAl & 125220 \\
\hline & & DEFA3 & 604522 \\
\hline & & DEFA5 & 600472 \\
\hline & & $D E F B 103 B$ & 606611 \\
\hline & & $S P A G 11 B$ & 606560 \\
\hline & & FАM90A7P & 613044 \\
\hline & & FAM90A10P & 613047 \\
\hline & & $D E F B 4 A$ & 602215 \\
\hline & & $C L D N 23$ & 609203 \\
\hline & & MFHAS1 & 605352 \\
\hline & & ERII & 608739 \\
\hline & & $P P P 1 R 3 B$ & 610541 \\
\hline & & $T N K S$ & 603303 \\
\hline
\end{tabular}

Duplication

\begin{tabular}{lllll}
\hline \multicolumn{2}{c}{ Patient 1} & & & \multicolumn{2}{c}{ Patient 2 } \\
\cline { 5 - 5 } Gene & OMIM & & Gene & OMIM \\
\hline ATP2C2 & 613082 & & WWOX & 605131 \\
COTL1 & 606748 & & MAF & 177075 \\
USP10 & 609818 & & MAFTRR & 616264 \\
CRISPLD2 & 612434 & & DYNLRB2 & 607168 \\
ZDHHC7 & 614604 & & CENPN & 611509 \\
KIAA0513 & 611675 & & ATMIN & 614693 \\
FAM92B & 617274 & & GCSH & 238330 \\
GSE1 & 616886 & & PKD1L2 & 607894 \\
GINS2 & 610609 & & BCO1 & 605748 \\
EMC8 & 604886 & & GAN & 605379 \\
COX4I1 & 123864 & & CMIP & 610112 \\
IRF8 & 601565 & & PLCG2 & 600220 \\
LINCO1082 & 614978 & & SDR42E1 & 616164 \\
LINCO1081 & 614977 & HSD17B2 & 109685 \\
FENDRR & 614975 & MPHOSPH6 & 605500 \\
FOXF1 & 601089 & CDH13 & 601364 \\
& & &
\end{tabular}

Table III. Continued.

Duplication

\begin{tabular}{|c|c|c|c|}
\hline \multicolumn{2}{|c|}{ Patient 1} & \multicolumn{2}{|c|}{ Patient 2} \\
\hline Gene & OMIM & Gene & OMIM \\
\hline MTHFSD & 616820 & $H S B P 1$ & 604553 \\
\hline$F O X C 2$ & 602402 & $M L Y C D$ & 606761 \\
\hline FOXL1 & 603252 & OSGINI & 607975 \\
\hline FBХO31 & 609102 & SLC $38 A 8$ & 615585 \\
\hline$M A P 1 L C 3 B$ & 609604 & MBTPS1 & 603355 \\
\hline ЈPHЗ & 605268 & $D N A A F 1$ & 613190 \\
\hline SLC7A5 & 600182 & $T A F 1 C$ & 604905 \\
\hline CA5A & 114761 & KCNG4 & 607603 \\
\hline$B A N P$ & 611564 & WFDC1 & 605322 \\
\hline ZNF469 & 612078 & $A T P 2 C 2$ & 613082 \\
\hline ZFPM1 & 601950 & COTL1 & 606748 \\
\hline IL17C & 604628 & USP10 & 609818 \\
\hline$C Y B A$ & 608508 & CRISPLD2 & 612434 \\
\hline$M V D$ & 603236 & ZDHHC7 & 614604 \\
\hline SNAI3 & 612741 & KIAA0513 & 611675 \\
\hline RNF166 & 617178 & FAM92B & 617274 \\
\hline CTU2 & 617057 & GSE1 & 616886 \\
\hline PIEZOI & 611184 & GINS2 & 610609 \\
\hline$C D T 1$ & 605525 & EMC8 & 604886 \\
\hline$A P R T$ & 102600 & COX4II & 123864 \\
\hline GALNS & 612222 & $I R F 8$ & 601565 \\
\hline TRAPPC $2 L$ & 610970 & LINC01082 & 614978 \\
\hline CBFA2T3 & 603870 & LINC01081 & 614977 \\
\hline$A C S F 3$ & 614245 & FENDRR & 614975 \\
\hline $\mathrm{CDH} 15$ & 114019 & $F O X F 1$ & 601089 \\
\hline ANKRDII & 611192 & MTHFSD & 616820 \\
\hline$S P G 7$ & 602783 & FOXC2 & 602402 \\
\hline RPL13 & 113703 & FOXL1 & 603252 \\
\hline CPNE7 & 605689 & FBXO31 & 609102 \\
\hline$D P E P 1$ & 179780 & $M A P 1 L C 3 B$ & 609604 \\
\hline CHMP1A & 164010 & $J P H 3$ & 605268 \\
\hline SPATA33 & 615409 & SLC7A5 & 600182 \\
\hline$C D K 10$ & 603464 & CA5A & 114761 \\
\hline ZNF276 & 608460 & $B A N P$ & 611564 \\
\hline FANCA & 607139 & ZNF469 & 612078 \\
\hline SPIRE2 & 609217 & ZFPM1 & 601950 \\
\hline$T C F 25$ & 612326 & IL17C & 604628 \\
\hline$M C 1 R$ & 155555 & $C Y B A$ & 608508 \\
\hline TUBB3 & 602661 & $M V D$ & 603236 \\
\hline$A F G 3 L 1 P$ & 603020 & SNAI3 & 612741 \\
\hline GAS8 & 605178 & RNF166 & 617178 \\
\hline GAS8-AS1 & 605179 & $C T U 2$ & 617057 \\
\hline URAHP & 615805 & PIEZOI & 611184 \\
\hline PRDM7 & 609759 & $C D T 1$ & 605525 \\
\hline & & $A P R T$ & 102600 \\
\hline & & GALNS & 612222 \\
\hline & & $T R A P P C 2 L$ & 610970 \\
\hline & & CBFA2T3 & 603870 \\
\hline & & $A C S F 3$ & 614245 \\
\hline
\end{tabular}


Table III. Continued.

Duplication

\begin{tabular}{|c|c|c|c|}
\hline \multicolumn{2}{|c|}{ Patient 1} & \multicolumn{2}{|c|}{ Patient 2} \\
\hline Gene & OMIM & Gene & OMIM \\
\hline & & CDH15 & 114019 \\
\hline & & ANKRDII & 611192 \\
\hline & & SPG7 & 602783 \\
\hline & & RPL13 & 113703 \\
\hline & & CPNE7 & 605689 \\
\hline & & DPEPl & 179780 \\
\hline & & CHMP1A & 164010 \\
\hline & & SPATA33 & 615409 \\
\hline & & CDK10 & 603464 \\
\hline & & ZNF276 & 608460 \\
\hline & & FANCA & 607139 \\
\hline & & SPIRE2 & 609217 \\
\hline & & TCF 25 & 612326 \\
\hline & & $M C 1 R$ & 155555 \\
\hline & & TUBB3 & 602661 \\
\hline & & $A F G 3 L 1 P$ & 603020 \\
\hline & & GAS8 & 605178 \\
\hline & & GAS8-AS1 & 605179 \\
\hline & & URAHP & 615805 \\
\hline & & PRDM7 & 609759 \\
\hline
\end{tabular}

OMIM, Online Mendelian Inheritance in Man.

151,472 kb being deleted (Fig. 2A). The deleted region of the tankyrase $(T N K S)$ gene began at the fifth intron. A duplication of $11.7 \mathrm{Mb}$ of the long arm of chromosome 16 with the proximal breakpoint between 76,961,103 bp (duplicated) and $76,938,723$ bp (normal) was observed and the last oligonucleotide present in the array at 16q position $88,690,571$ bp was duplicated (Fig. 2B). The size of the breakpoint intervals were $13,874 \mathrm{bp}$ for $8 \mathrm{p}$ and $22,380 \mathrm{bp}$ for $16 \mathrm{q}$. The analysis revealed an unbalanced translocation and the aCGH karyotype was 46,XX,der(8)t(8;16)(p23.1;q23.1).arr[hg18]8p23.3p23.1 $(151,472-9548146) \times 1,16 q 23.1 q 24.3(76,961,103-88,690,571) \times 3$.

A list of OMIM genes deleted and duplicated is presented in Table III. Microsatellite analysis of the trio revealed that deletion and duplication occurred on maternally-derived chromosomes (Table IV).

Bioinformatic analyses. A possible cause of rearrangements, duplications and deletions is the occurrence of recombination events. To search for a possible breakpoint for recombination, the BLAST algorithm was used to find sequence similarity in the breakpoint regions of the two patients. The breakpoint regions were revealed to contain similar sequences residing in Alu elements of Patient 1 and in L1 elements of Patient 2.

The rearranged regions were viewed in parallel with ISCA consortium data in the UCSC Genome Browser. The $8 \mathrm{p}$ region contained multiple pathogenic copy number variations
(74 deletions and 31 duplications) described in the ISCA database, while rearrangements in $16 \mathrm{q}$ were less frequent (containing 19 deletions and 16 duplications). Manual computations of the ISCA data revealed that $66 \%$ of patients with 8p23.3-p23.1 rearrangements (deletions or duplications), and $62 \%$ of patients with 16q23.1-q24.3 rearrangements had developmental delay in their pathogenic phenotype (Fig. 3).

\section{Discussion}

To the best of our knowledge, this is the first report of a rearrangement involving an $8 \mathrm{p}$ deletion and $16 \mathrm{q}$ duplication. The two patients presented in this report had subtle facial feature dysmorphia, dysmorphic body features, borderline intelligence and marginal follow up progress, low birth weight and vertebral anomalies, and one presented with cardiovascular abnormalities. The majority of the clinical characteristics of the two patients were associated with those of $8 p$ or $16 q$ chromosome imbalances, but it is difficult to estimate if the clinical phenotype and developmental delay were due to the rearrangement or whether they were the result of $8 p$ monosomy and $16 q$ trisomy separately. It has previously been recognized that deletions in the distal region of chromosome $8 \mathrm{p}$ are associated with growth and mental impairment, minor facial dysmorphisms, microcephaly, congenital heart defects and behavioral problems (23). According to all references, $16 \mathrm{q}$ trisomy is a rare abnormality due to high rates of mortality and lethality in the prenatal and neonatal period $(11,24)$. Partial 16q trisomy is most often the result of balanced or unbalanced rearrangements, and therefore it is difficult to understand if the commonly observed phenotypic characteristics (dysmorphic facial features, developmental delay, intellectual disability, central nervous system malformations and congenital heart defects) are due to 16q or whether they are the result of changes in genome architecture (24).

More than 2/3 of patients with $8 p$ syndrome have congenital heart defects, suggesting that 8 p23.1 maybe critical for heart development $(5,25)$. One of the candidate genes for heart disease is GATA4 because haploinsufficiency and mutations have been documented in patients and families with atrial septal defects and other cardiac defects associated with 8p23.1 deletion (4,26-29). Chen et al (30) studied a four-generation Chinese atrial septal defect family and suggested that a mutation in the GATA4 gene (c.A899C, p.K300T) may contribute to this congenital heart disease. However, the GATA4 gene was not deleted in either patient in the present study. The fact that Patient 1 has heart problems suggested either that other genes were responsible for these problems, or that the rearrangement resulted in a structural alteration affecting the function of genes associated with the heart. The CSMD1 gene (8p23.2) was deleted in Patient 2 but only partially deleted in Patient 1 . According to the literature, CSMDI loss of function is correlated with head and neck squamous cell carcinoma $(31,32)$, and liver $(33,34)$, lung, breast and skin cancers $(31)$. Deletion of this gene has been reported in a case of craniofacial and body dysmorphisms and mental retardation (35). In Patient 2, two of the deleted genes were TNKS and MCPHI. These genes are involved in meiosis and mitosis mechanisms. The TNKS gene, located at 8p23.1, is involved in sister chromatid cohesion and deletions result in anaphase arrest (36). Páez et al (4) identified deletions of $T N K S$ gene in patients with mental retardation and 
Table IV. Results from microsatellite analysis on Patient 2.

\begin{tabular}{lcccc}
\hline Sample & $253-10$ Proband & $254-10$ father & $255-10$ mother & Origin \\
\hline D8S201 & 259.5 & $255.5 / 259.5$ & $259.5 / 267.2$ & Uninformative \\
D8S504 & 200.7 & $200.7 / 202.8$ & $198.1 / 202.7$ & Maternal \\
D8S264 & 138.2 & $138.1 / 138.1$ & $126.4 / 126.4$ & Maternal \\
D8S1781 & 259.4 & $259.4 / 263.2$ & $251.1 / 263.1$ & Maternal \\
D8S351 & 119.2 & $119 / 119$ & $105 / 105$ & Maternal \\
D8S1706 & $228 / 234.2$ & $228 / 234.2$ & $228 / 234.2$ & Uninformative \\
D16S3023 & $79.5 / 83.5$ & $83.5 / 83.5$ & $79.5 / 83.6$ & Uninformative \\
D16S413 & $128 / 132$ & $130 / 132$ & $128 / 132$ & Uninformative \\
STS1 (chr16) & $210.8 * / 214.9$ & $214.9 / 214.9$ & $125.2 / 125.2$ & Maternal \\
STS2 (chr16) & $125.2 / 125.2$ & $125.2 / 125.2$ & Uninformative \\
STS3 (chr16) & $296.5 / 296.5$ & $294.6 / 296.5$ & $345.4 / 357.38$ & Uninformative \\
STS4 (chr16) & $345.32 / 352.4 / 357.8$ & $352.4 / 359.7$ & Maternal \\
\hline
\end{tabular}

Polymorphic sequence tagged site markers were selected in the deleted and duplicated regions of chromosomes 8 and 16 , respectively.

A 8

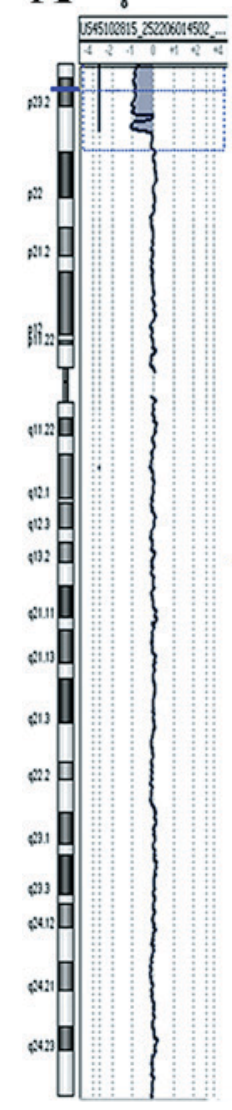

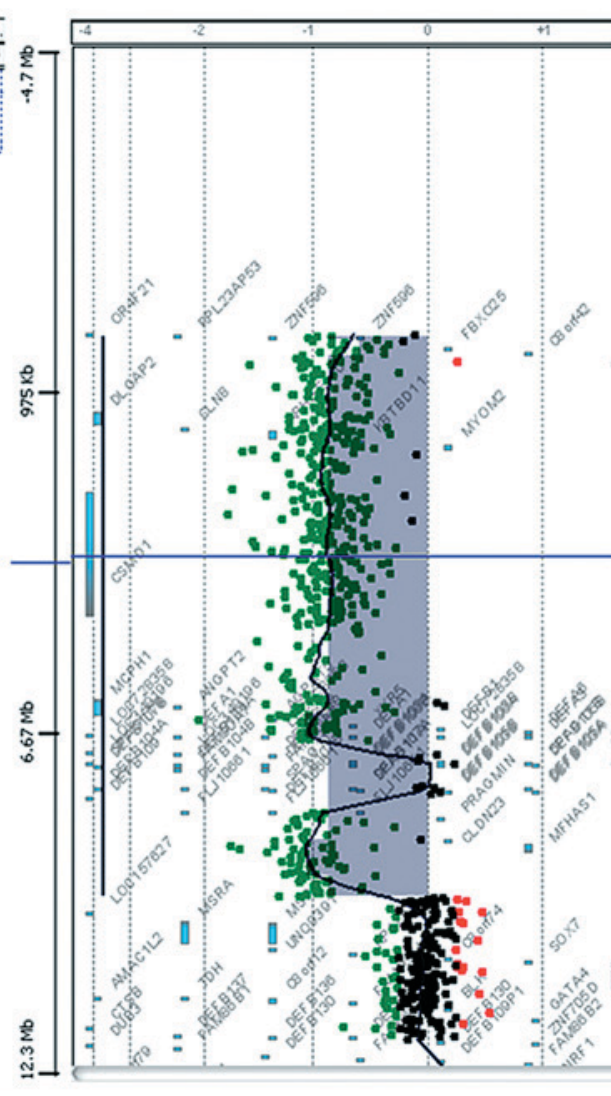

B

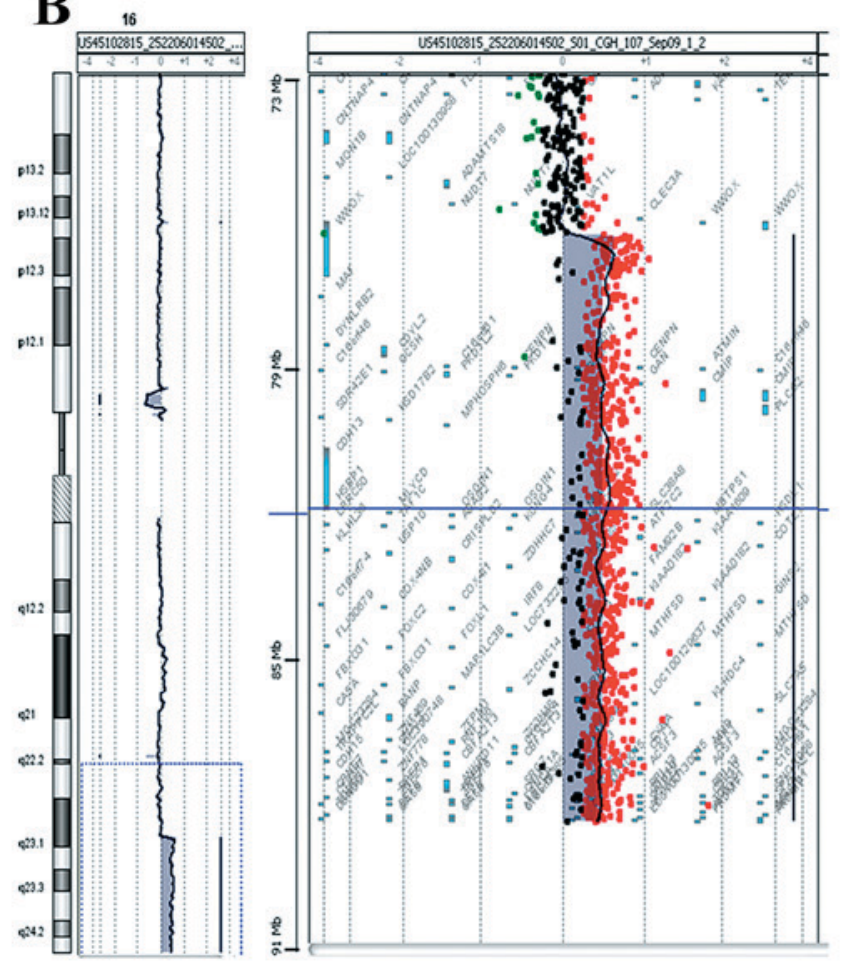

Figure 2. Array comparative genomic hybridization results for Patient 2. (A) De novo 9,5 Mb deletion in the short arm of chromosome 8 located at the $8 \mathrm{p} 23$ to 8pter. (B) De novo $11,7 \mathrm{Mb}$ duplication in the long arm of chromosome 16 located at the $16 \mathrm{q} 23.1$ to $16 \mathrm{qter}$.

behavioral problems. TNKS protein positively regulates the Wnt/ $\beta$-catenin signaling pathway (37). This pathway is critical for healthy embryonic development and cellular differentiation (38). Furthermore, TNKS is a candidate gene for Cornelia de Lange Syndrome (CdLS) $(3,36)$, a syndrome characterized by distinctive facial features including well-defined curved and confluent eyebrows, long eyelashes, anteverted nares, micrognathia and downturned corners of the mouth with a thin upper lip. Patient 2 resembled the CdLS facial phenotype, and she is expected to have psychomotor retardation, language acquisition difficulties and behavioral disorders in the autistic spectrum, typical aspects of CdLS. The MCPH1 


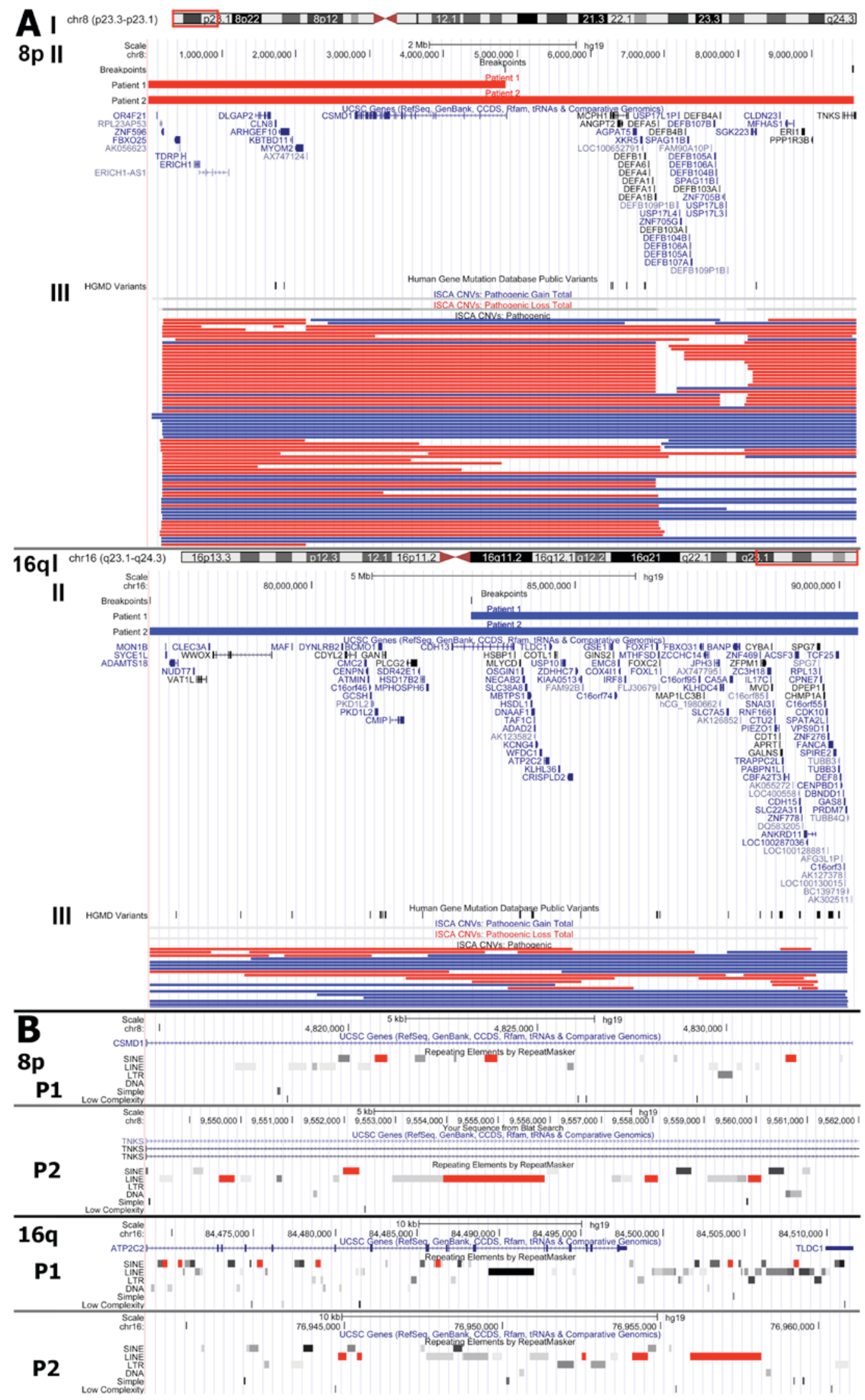

Figure 3. (A) Sequence features of the 8p and 16q translocated regions. The features are presented in parallel tracks. I) Chromosome ideogram representing the translocated regions in the red square. II) Chromosome positions of deleted (in red) and duplicated (in blue) regions are shown in each patient and respective breakpoints and gene positions are highlighted. III) Pathogenic copy number variants in these regions, as published by the ISCA Consortium. Blue lines represent duplications and red lines deletions. (B) Sequence features of the respective $8 \mathrm{p}$ and $16 \mathrm{q}$ breakpoints for both patients. Presented in parallel tracks: the chromosome scale and chromosome region annotation, genes present in this chromosome region and repetitive genetic elements as annotated by the RepeatMasker tool (www.repeatmasker.org). Red color repeats denote sequences with high similarity, as revealed by BLAST alignment of the respective breakpoints for each patient. P1, patient 1; P2, patient 2. 
gene, additionally located in $8 \mathrm{p} 23.1$, is involved in preventing cells from prematurely entering mitosis, and truncated mutations have been associated with premature chromosome condensation and were observed in patients with microcephaly, growth impairment and mental retardation $(36,39)$. Another gene located in 8p23.1 is RP1 like 1 (RPILI). Its expression is restricted to the postnatal retina, potentially being involved in retinal development (40). The RP1L1 gene may not be haploinsufficient in Patient 2, who was diagnosed with diffuse depigmentation of the retina. This gene maybe under the control of translocated regulatory elements, being in the proximity of the breakpoint, and may have resulted in this retinal disorder.

In total, $>30$ cases with distal $8 p$ deletion have been described in the literature, and 9 with 16q24 duplication, but only a few have been characterized with high resolution molecular techniques $(1,11)$. The $8 \mathrm{p}$ region is more often reported to be involved in rearrangements than 16q. Giglio et al (41) demonstrated that the olfactory receptor (OR) gene clusters are the substrate for the formation of intrachromosomal rearrangements involving chromosome $8 \mathrm{p}$. Different rearrangements, most of them recurring, are associated with the distal 8p region. Among them there are inv dup(8p), del(8p22) and small marker chromosomes der(8)(p23-pter) (41). Furthermore, seven individuals with balanced and unbalanced translocations between 4 p16 and 8p23 demonstrated that the breakpoints fell within the $4 \mathrm{p}$ and $8 \mathrm{p}$ OR-gene clusters (42).

BLAST alignment in the $8 \mathrm{p}$ and $16 \mathrm{q}$ regions revealed high similarity regions with several Alu elements in Patient 1 and two similar long interspersed nuclear element 1 elements in Patient 2. Retroelements are known to facilitate recombination events (43). Consequently, a potential mechanism of their appearance maybe unequal cross over between repetitive DNA regions with high sequence similarity (44). The deleted and duplicated regions are regions often correlated with developmental delay, according to the ISCA Consortium (20).

Novel diagnostic methods with great potential have facilitated the study and interpretation of the consequences of chromosome aberrations and revealed that the pathogenicity may be due to complex molecular mechanisms $(45,46)$. A number of the genes identified as deleted or duplicated in these cases may have resulted in developmental delay, but developmental delay may also be the result of rearrangements and changes of important parts of gene structure functional elements, truncated or fusion genes. A multidisciplinary effort aiming to study all cases with $8 \mathrm{p} ; 16 \mathrm{q}$ rearrangements with combined and accurate methods and tools (cytogenetic, molecular cytogenetic, NGS mapping) along with their clinical phenotypes may elucidate the involvement of the rearrangement, genes involved, participation of control elements and/or interactions with polymorphic regions, and potentially a clear phenotype-genotype correlation.

\section{References}

1. Reddy KS: A paternally inherited terminal deletion, del(8)(p23.1) pat, detected prenatally in an amniotic fluid sample: A review of deletion 8p23.1 cases. Prenat Diagn 19: 868-872, 1999.

2. Fagan KA and Morris RB: Del(4)(q33-qter): Another case report of a child with mild dysmorphism. J Med Genet 26: 776-778, 1989.
3. Ballarati L, Cereda A, Caselli R, Selicorni A, Recalcati MP, Maitz S, Finelli P, Larizza L and Giardino D: Genotype-phenotype correlations in a new case of 8 p23.1 deletion and review of the literature. Eur J Med Genet 54: 55-59, 2011.

4. Páez MT, Yamamoto T, Hayashi K, Yasuda T, Harada N, Matsumoto N, Kurosawa K, Furutani Y, Asakawa S, Shimizu N and Matsuoka R: Two patients with atypical interstitial deletions of 8p23.1: Mapping of phenotypical traits. Am J Med Genet A 146A: 1158-1165,2008.

5. Devriendt K, Matthijs G, Van Dael R, Gewillig M, Eyskens B, Hjalgrim H, Dolmer B, McGaughran J, Bröndum-Nielsen K, Marynen P, et al: Delineation of the critical deletion region for congenital heart defects, on chromosome 8p23.1. Am J Hum Genet 64: 1119-1126, 1999.

6. Shin WJ, Kim SD and Kim KH: The general anesthesia experience of deletion $8 \mathrm{p}$ syndrome patient-A case report. Korean $\mathrm{J}$ Anesthesiol 61: 332-335, 2011.

7. Brisset S, Joly G, Ozilou C, Lapierre JM, Gosset P, LeLorc'h M, Raoul O, Turleau C, Vekemans M and Romana SP: Molecular characterization of partial trisomy 16q24.1-qter: Clinical report and review of the literature. Am J Med Genet 113: 339-345, 2002.

8. Ferrero GB, Belligni E, Sorasio L, Delmonaco AG, Oggero R, Faravelli F, Pierluigi M and Silengo M: Phenotype resembling donnai-barrow syndrome in a patient with 9qter;16qter unbalanced translocation. Am J Med Genet A 140: 892-894, 2006.

9. Hutchinson R, Wilson M and Voullaire L: Distal 8p deletion (8p23.1-8pter): A common deletion? J Med Genet 29: 407-411, 1992.

10. Zahn S, Ehrbrecht A, Bosse K, Kalscheuer V, Propping P, Schwanitz G, Albrecht B and Engels H: Further delineation of the phenotype maps for partial trisomy 16q24 and jacobsen syndrome by a subtle familial translocation $\mathrm{t}(11 ; 16)(\mathrm{q} 24.2 ; \mathrm{q} 24.1)$. Am J Med Genet A 139: 19-24, 2005.

11. Zhou Y, Yao Q, Cui YX, Yao B, Fan K, Xia XY, Hu YA and Li XJ: Clinical and cytogenetic characterization of a boy with a de novo pure partial trisomy 16q24.1q24.3 and complex chromosome rearrangement. Am J Med Genet A 161A: 897-900, 2013.

12. Burnside RD, Pappas JG, Sacharow S, Applegate C, Hamosh A, Gadi IK, Jaswaney V, Keitges E, Phillips KK, Potluri VR, et al: Three cases of isolated terminal deletion of chromosome $8 \mathrm{p}$ without heart defects presenting with a mild phenotype. Am J Med Genet A 161A: 822-828, 2013.

13. Baker E, Hinton L, Callen DF, Altree M, Dobbie A, Eyre HJ, Sutherland GR, Thompson E, Thompson P, Woollatt E and Haan E: Study of 250 children with idiopathic mental retardation reveals nine cryptic and diverse subtelomeric chromosome anomalies. Am J Med Genet 107: 285-293, 2002.

14. Giardino D, Finelli P, Gottardi G, Clerici D, Mosca F, Briscioli V and Larizza L: Cryptic subtelomeric translocation $\mathrm{t}(2 ; 16)$ (q37;q24) segregating in a family with unexplained stillbirths and a dysmorphic, slightly retarded child. Eur J Hum Genet 9: 881-886, 2001.

15. Maher ER, Willatt L, Cuthbert G, Chapman C and Hodgson SV: Three cases of 16q duplication. J Med Genet 28: 801-802, 1991.

16. Bayley N: Scales of Infant Development. 2nd edition. The Psychological Corporation, San Antonio, TX, 1993.

17. Griffiths R: A comprehensive system of measurement for the first eight years of life. In: The Abilities of Young Children. Bucks: Association for Research in Infant and Child Development. The test Agency, Oxford, pp101-172, 1984

18. Manolakos E, Peitsidis P, Eleftheriades M, Dedoulis E, Ziegler M, Orru S, Liehr T and Petersen MB: Prenatal detection of full monosomy 21 in a fetus with increased nuchal translucency: Molecular cytogenetic analysis and review of the literature. J Obstet Gynaecol Res 36: 435-440, 2010.

19. Kent WJ, Sugnet CW, Furey TS, Roskin KM, Pringle TH, Zahler AM and Haussler D: The human genome browser at UCSC. Genome Res 12: 996-1006, 2002.

20. Kaminsky EB, Kaul V, Paschall J, Church DM, Bunke B, Kunig D, Moreno-De-Luca D, Moreno-De-Luca A, Mulle JG, Warren ST, et al: An evidence-based approach to establish the functional and clinical significance of copy number variants in intellectual and developmental disabilities. Genet Med 13: 777-784, 2011.

21. Miller DT, Adam MP, Aradhya S, Biesecker LG, Brothman AR, Carter NP, Church DM, Crolla JA, Eichler EE, Epstein CJ, et al: Consensus statement: Chromosomal microarray is a first-tier clinical diagnostic test for individuals with developmental disabilities or congenital anomalies. Am J Hum Genet 86: 749-764, 2010. 
22. Altschul SF, Gish W, Miller W, Myers EW and Lipman DJ: Basic local alignment search tool. J Mol Biol 215: 403-410, 1990.

23. Digilio MC, Marino B, Guccione P, Giannotti A, Mingarelli R and Dallapiccola B: Deletion 8p syndrome. Am J Med Genet 75 534-536, 1998

24. Lonardo F, Perone L, Maioli M, Ciavarella M, Ciccone R, Monica MD, Lombardi C, Forino L, Cantalupo G, Masella L and Scarano F: Clinical, cytogenetic and molecular-cytogenetic characterization of a patient with a de novo tandem proximal-intermediate duplication of $16 \mathrm{q}$ and review of the literature. Am J Med Genet A 155A: 769-777, 2011.

25. Johnson MC, Hing A, Wood MK and Watson MS: Chromosome abnormalities in congenital heart disease. Am J Med Genet 70 292-298, 1997.

26. Mei M, Yang L, Zhan G, Wang H, Ma D, Zhou W and Huang G: Analysis of genomic copy number variations in two unrelated neonates with $8 p$ deletion and duplication associated with congenital heart disease. Zhonghua Er Ke Za Zhi 52: 460-463, 2014 (In Chinese).

27. Pehlivan T, Pober BR, Brueckner M, Garrett S, Slaugh R, Van Rheeden R, Wilson DB, Watson MS and Hing AV: Gata4 haploinsufficiency in patients with interstitial deletion of chromosome region 8p23.1 and congenital heart disease. Am J Med Genet 83: 201-206, 1999.

28. Wat MJ, Shchelochkov OA, Holder AM, Breman AM, Dagli A, Bacino C, Scaglia F, Zori RT, Cheung SW, Scott DA and Kang SH: Chromosome 8p23.1 deletions as a cause of complex congenital heart defects and diaphragmatic hernia. Am J Med Genet A 149A: 1661-1677, 2009.

29. Yang YQ, Wang J, Liu XY, Chen XZ, Zhang W, Wang XZ, Liu X and Fang WY: Novel GATA4 mutations in patients with congenital ventricular septal defects. Med Sci Monit 18: CR344-CR350, 2012.

30. Chen J, Qi B, Zhao J, Liu W, Duan R and Zhang M: A novel mutation of GATA4 (K300T) associated with familial atrial septal defect. Gene 575: 473-477, 2016.

31. Ma C, Quesnelle KM, Sparano A, Rao S, Park MS, Cohen MA, Wang Y, Samanta M, Kumar MS, Aziz MU, et al: Characterization CSMD1 in a large set of primary lung, head and neck, breast and skin cancer tissues. Cancer Biol Ther 8: 907-916, 2009.

32. Toomes C, Jackson A, Maguire K, Wood J, Gollin S, Ishwad C, Paterson I, Prime S, Parkinson K, Bell S, et al: The presence of multiple regions of homozygous deletion at the CSMD1 locus in oral squamous cell carcinoma question the role of CSMD1 in head and neck carcinogenesis. Genes Chromosomes Cancer 37 132-140, 2003

33. Midorikawa Y, Yamamoto S, Tsuji S, Kamimura N, Ishikawa S, Igarashi $\mathrm{H}$, Makuuchi M, Kokudo N, Sugimura $\mathrm{H}$ and Aburatani H: Allelic imbalances and homozygous deletion on $8 \mathrm{p} 23.2$ for stepwise progression of hepatocarcinogenesis. Hepatology 49: 513-522, 2009.

34. Zhu Q, Gong L, Liu X, Wang J, Ren P, Zhang W, Yao L, Han X, Zhu S, Lan M, et al: Loss of heterozygosity at D8S262: An early genetic event of hepatocarcinogenesis. Diagn Pathol 10: 70, 2015.
35. Naseer MI, Chaudhary AG, Rasool M, Kalamegam G, Ashgan FT, Assidi M, Ahmed F, Ansari SA, Zaidi SK, Jan MM and Al-Qahtani MH: Copy number variations in Saudi family with intellectual disability and epilepsy. BMC Genomics 17 (Suppl 9): S757, 2016.

36. Baynam G, Goldblatt J and Walpole I: Deletion of 8p23.1 with features of Cornelia de Lange syndrome and congenital diaphragmatic hernia and a review of deletions of $8 \mathrm{p} 23.1$ to 8pter? A further locus for Cornelia de Lange syndrome. Am J Med Genet A 146A: 1565-1570, 2008.

37. Roy S, Liu F and Arav-Boger R: Human Cytomegalovirus Inhibits the PARsylation Activity of Tankyrase-A potential strategy for suppression of the Wnt pathway. Viruses 8: pii: E8, 2015.

38. Clevers $\mathrm{H}$ and Nusse R: Wnt/ $\beta$-catenin signaling and disease. Cell 149: 1192-1205, 2012.

39. Trimborn M, Bell SM, Felix C, Rashid Y, Jafri H, Griffiths PD, Neumann LM, Krebs A, Reis A, Sperling K, et al: Mutations in microcephalin cause aberrant regulation of chromosome condensation. Am J Hum Genet 75: 261-266, 2004.

40. Conte I, Lestingi M, den Hollander A, Alfano G, Ziviello C, Pugliese M, Circolo D, Caccioppoli C, Ciccodicola A and Banfi S: Identification and characterisation of the retinitis pigmentosa 1-like1 gene (RP1L1): A novel candidate for retinal degenerations. Eur J Hum Genet 11: 155-162, 2003.

41. Giglio S, Calvari V, Gregato G, Gimelli G, Camanini S, Giorda R, Ragusa A, Guerneri S, Selicorni A, Stumm M, et al: Heterozygous submicroscopic inversions involving olfactory receptor-gene clusters mediate the recurrent $\mathrm{t}(4 ; 8)(\mathrm{p} 16 ; \mathrm{p} 23)$ translocation. Am J Hum Genet 71: 276-285, 2002

42. Giglio S, Broman KW, Matsumoto N, Calvari V, Gimelli G, Neumann T, Ohashi H, Voullaire L, Larizza D, Giorda R, et al: Olfactory receptor-gene clusters, genomic-inversion polymorphisms, and common chromosome rearrangements. Am J Hum Genet 68: 874-883, 2001.

43. Konkel MK and Batzer MA: A mobile threat to genome stability: The impact of non-LTR retrotransposons upon the human genome. Semin Cancer Biol 20: 211-221, 2010.

44. Robberecht C, Voet T, Zamani Esteki M, Nowakowska BA and Vermeesch JR: Nonallelic homologous recombination between retrotransposable elements is a driver of de novo unbalanced translocations. Genome Res 23: 411-418, 2013.

45. Newman S, Hermetz KE, Weckselblatt B and Rudd MK: Next-generation sequencing of duplication CNVS reveals that most are tandem and some create fusion genes at breakpoints. Am J Hum Genet 96: 208-220, 2015.

46. Utami KH, Hillmer AM, Aksoy I, Chew EG, Teo AS, Zhang Z, Lee CW, Chen PJ, Seng CC, Ariyaratne PN, et al: Detection of chromosomal breakpoints in patients with developmental delay and speech disorders. PLoS One 9: e90852, 2014. 